\title{
Can Our Hearts Take the New Guidelines?
}

\author{
Eitan Frankel, MD
}

\begin{abstract}
After getting sign-out for the Heart Failure service, I excitedly went to meet Mr. G. Two months ago, while on a different service, I frequently watched him bustle through the hospital hallways with his IV pole in hand. He smiled, spoke cordially with nurses and staff, and took time to greet house-staff not directly involved with his care. Thus, you can imagine my surprise when I entered his room and encountered a forlorn face with a few days of stubble complaining about cold eggs and toast. He hadn't been on a walk in days.
\end{abstract}

Unfortunately, the scene I am describing is likely familiar to anyone involved with inpatient, heart failure care. Mr. $G$ is a 67 year-old-male with ischemic cardiomyopathy (left ventricular ejection fraction 10-15\%) on outpatient milrinone who was admitted for expedited heart transplant evaluation in the setting of worsening symptoms and hemodynamics. His milrinone was increased to the maximum dose and a Swan Ganz catheter was placed. In early September 2018, he was listed as status $1 \mathrm{~A}$, the highest level prior to transplant. For the next month, Mr. G cheerfully greeted the resident at 7am, persuaded nurses to slip him extra chocolate, and set new records on his daily walks.

Then overnight, on October $18^{\text {th }} 2018$, the new transplant listing criteria went into effect and everything changed. Allocation of organ transplantation in the United States is managed by the United Network for Organ Sharing (UNOS) and is dependent on an intricate system. Due to the relative scarcity, there is no easy way to justly and effectively allocate hearts. Over the past few years, there had been a growing consensus that the old listing system had significant problems: there were too many status $1 \mathrm{~A}$ patients, there was inadequate organ allocation to certain high risk candidates, allocation rules were not aligned with prognosis, and there were unintended geographic disparities. ${ }^{1}$ Thus, in October, a new set of guidelines went into effect that changed the criteria for urgency status (Table 1) and increased the geographical distance for organ procurement to 500 miles. $^{2}$ According to the new guidelines, only three categories of patients are considered Status 1: those on VA ECMO (who can be listed as Status 1 for 7 days), those who are non-dischargeable with biventricular devices, and those who have mechanical circulatory support devices and life-threatening arrhythmias. ${ }^{2}$ These changes to the criteria for medical urgency in orthotopic heart transplants were not unexpected, but there remain unsolved system-wide and patient-centered questions that the cardiology community needs to address.
One question is what will happen to the metric of one-year survival after transplant? While one-year survival has traditionally been the gold standard for evaluating transplant programs, historical data suggests that if programs elect to transplant the highest risk patients (i.e. ECMO patients), outcomes will worsen. Since the 1980s, the International Society for Heart and Lung Transplantation (ISHLT) has compiled a registry of 141,268 heart transplants and published an annual report with statistics and outcome data. ${ }^{3}$ As mechanical circulatory support (MCS) has become safer and more efficacious, an increasing number of transplants are being bridged by MCS (26.0\% from 2004 to 2008 vs. 43.0\% from 2009-2014). ${ }^{3}$ While patients with left ventricular assist devices, biventricular assist devices, and no mechanical support (plus or minus inotropes) do comparably well after transplant, extracorporeal membrane oxygenation (ECMO) patients continue to lag in their one-year survival rates (80-85\% vs 60\%, $\mathrm{p}<.05) .{ }^{4}$ A separate retrospective cohort study looking at post-heart transplant mortality among 157 ECMO-supported adults between 2000 and 2015 demonstrated similar results. The overall one-year survival rate was $57.8 \%$, and it was significantly worse among patients with renal insufficiency (defined as GFR $<45 \mathrm{ml} / \mathrm{min} / 1.73 \mathrm{~m} 2$ or dialysis dependent), mechanical ventilation, or both of these comorbidities $152.3 \%$ vs $55.3 \%$ vs $12.5 \%) .{ }^{4}$ It is important to note that there are significant limitations to each of these studies; both studies were retrospective and did not evaluate center expertise. While it is possible transplant outcomes among ECMO patients may improve with increasing usage and familiarity, it is unlikely that 1-year survival will reach the $90 \%$ one-year survival benchmark to which programs are currently held accountable. Given this existing historical data, current transplant programs will have to make a difficult decision: whether to take advantage of increased donor availability for Status $1 \mathrm{~A}$ patients and accept the risk of transplanting high-risk patients, or whether to defer operating on these patients in order to protect outcome statistics.

While the validity of one-year survival as a metric of transplant program success is only one of many system-wide issues related to the new guidelines, this conversation would be incomplete without returning to the case of Mr. G and focusing on the patient-centered effects. Even though Mr. G did not miraculously improve or titrate off inotropes, overnight his listing status changed from $1 \mathrm{~A}$ to 3 . At a statistical level, the outcomes of old Status $1 \mathrm{~A}$ and new Status 3 can be compared. 
Table 1: PFTs from September 2016

\section{Criteria Requirements in Adult Heart Allocation Policy}

\begin{tabular}{|c|c|c|c|}
\hline \multicolumn{2}{|r|}{ Old Guidelines } & \multicolumn{2}{|r|}{ New Guidelines } \\
\hline Status & Criteria & Status & Criteria \\
\hline $1 \mathrm{~A}$ & $\begin{array}{l}\text { "Transplant candidate must be admitted to listing } \\
\text { transplant center hospital and have at least one of the } \\
\text { following devices or therapies in place: } \\
\text { 1) Mechanical circulatory support for acute hemodynamic } \\
\text { decompensation (LVAD <30 days, } \\
\text { TAH, IABP, ECMO) } \\
\text { 2) MCS with device complications } \\
\text { 3) Continuous mechanical ventilation } \\
\text { 4) Continuous infusion of a single high-dose intravenous } \\
\text { inotrope or multiple intravenous inotropes, in addition to } \\
\text { continuous hemodynamic monitoring of left ventricular } \\
\text { filling pressures" }\end{array}$ & 3 & $\begin{array}{l}\text { "1) VA ECMO } \\
\text { 2) Non-dischargeable, surgically implanted, non-endovascular } \\
\text { biventricular support device } \\
\text { 3) MCSD with life-threatening ventricular arrhythmias" } \\
\text { "1) Non-dischargeable, surgically implanted, non-endovascular LVAD } \\
\text { 2) IABP } \\
\text { 3) Vtach/Vfib } \\
\text { 4) MCSD with device malfunction } \\
\text { 5) TAH, BiVAD, RVAD, or VAD } \\
\text { 6) Percutaneous endovascular MCSD " } \\
\text { "1) Dischargeable LVAD (<30 days) } \\
\text { 2) Multiple inotropes or single high-dose inotrope with continuous } \\
\text { hemodynamic monitoring } \\
\text { 3) VA ECMO after } 7 \text { days; percutaneous endovascular circulatory } \\
\text { support device or IABP after } 14 \text { days } \\
\text { 4) Non-dischargeable, surgically implanted, non-endovascular LVAD } \\
\text { after } 14 \text { days } \\
\text { 5) MCSD with device infection. hemolysis, pump thrombosis, right heart } \\
\text { failure, mucosal bleeding, aortic insufficiency" }\end{array}$ \\
\hline $1 \mathrm{~B}$ & $\begin{array}{l}\text { "Transplant candidate listed must have at least one of the } \\
\text { following devices or therapies in place: } \\
\text { 1) Left and/or right ventricular assist device implanted } \\
\text { 2) Continuous infusion of intravenous inotropes" } \\
\text { A transplant candidate who does not meet the criteria for } \\
\text { Status 1A or 1B }\end{array}$ & 4 & $\begin{array}{l}\text { "1) Dischargeable LVAD } \\
\text { 2) Inotrope without hemodynamic monitoring } \\
\text { 3) Re-transplant } \\
\text { 4) Congenital heart disease, intractable angina, HCM, restrictive cardio- } \\
\text { myopathy, amyloidosis" }\end{array}$ \\
\hline 7 & $\begin{array}{l}\text { A transplant candidate who is considered temporarily } \\
\text { unsuitable to receive a heart transplant }\end{array}$ & $\begin{array}{l}5 \\
6\end{array}$ & $\begin{array}{l}\text { On the waitlist for at least one other organ at the same hospital } \\
\text { All remaining active candidates }\end{array}$ \\
\hline
\end{tabular}

This data will take a few years to collect, but hopefully our patients will do just as well as before. But much more difficult to measure will be the emotional and psychological effects of the shifting guidelines on current transplant candidates.

Mr. G was devastated when he heard his status had been downgraded to Status 3. After remaining upbeat and hopeful for months, while feeling that he was slowly approaching the end of the tunnel, he suddenly had no idea if or when he might receive a transplant. The unpaid bills at home and his familial responsibilities started taking a toll on his mood, and the once hospital marathoner grew increasingly despondent and frustrated; he frequently discussed leaving the hospital without a new heart. And while he understood that that there were valid reasons behind the guideline changes, he still felt betrayed by the system and the fact that he wasn't grandfathered in.

And I don't blame him one bit.

\section{REFERENCES}

1. Fudim M. The Future of the Adult Heart Allocation System in the United States [Internet]. American College of Cardiology. 2017 [cited 2018 Dec 19];Available from: https://www.acc.org/latest-in-cardiology/articles/2017/02/09/07/24/ the-future-of-the-adult-heart-allocation-system-in-the-us.

2. Adult Heart Allocation [Internet]. Organ Procurement and Transplantation Network. 2018 [cited 2018 Dec 19]; Available from: https://optn.transplant.hrsa gov/learn/professional-education/adult-heart-allocation/

3. Yusen RD, Edwards LB, Kucheryavaya AY, Benden C, Dipchand Al, Goldfarb SB, Levvey BJ, Lund LH, Meiser B, Rossano JW, Stehlik J. The Registry of the International Society for Heart and Lung Transplantation: Thirty-second Official Adult Lung and Heart-Lung Transplantation Report-2015; Focus Theme: Early Graft Failure. The Journal of Heart and Lung Transplantation. 2015;34: 1264-1277.

4. Zalawadiya S, Fudim M, Bhat G, Cotts W, Lindenfeld J. Extracorporeal membrane oxygenation support and post-heart transplant outcomes among United States adults. The Journal of Heart and Lung Transplantation. 2017;36: 77-81. 